\title{
Polyamide 66/Brazilian Clay Nanocomposites
}

\author{
E. M. Araújo, ${ }^{1}$ K. D. Araujo, ${ }^{1}$ R. A. Paz, ${ }^{1}$ T. R. Gouveia, ${ }^{1}$ R. Barbosa, ${ }^{1}$ and E. N. Ito ${ }^{2}$ \\ ${ }^{1}$ Department of Materials Engineering, Federal University of Campina Grande, Avenida Aprígio Veloso, 882, Bodocongó, \\ CEP 58429-900, Campina Grande, PB, Brazil \\ ${ }^{2}$ Department of Materials Engineering, Federal University of São Carlos, CEP 13565-905, São Carlos, SP, Brazil
}

Correspondence should be addressed to E. M. Araújo, edcleide@dema.ufcg.edu.br

Received 7 July 2008; Accepted 10 October 2008

Recommended by Jose A. Pomposo

\begin{abstract}
Polyamide 66 (PA66)/Brazilian clay nanocomposites were produced via direct melt intercalation. A montmorillonite sample from the Brazilian state of Paraíba was organically modified with esthearildimethylammonium chloride (Praepagen), quaternary ammonium salt and has been tested to be used in polymer nanocomposites. The dispersion analysis and the interlayer spacing of the clay particles in matrix were investigated by X-ray diffraction (XRD) and transmission electron microscopy (TEM). Thermal behavior of the obtained systems was investigated by differential scanning calorimetry (DSC), thermogravimetry (TG), and heat deflection temperature (HDT) was reported too. The nanocomposites exhibited a partially exfoliated structure, very interesting HDT values which are higher than those of pure PA66, and good thermal stability.
\end{abstract}

Copyright ( 2009 E. M. Araújo et al. This is an open access article distributed under the Creative Commons Attribution License, which permits unrestricted use, distribution, and reproduction in any medium, provided the original work is properly cited.

\section{Introduction}

Polymer/organoclay nanocomposites present unique properties that are not observed in conventional composites. Incorporation of small amounts of organoclay (<10 wt.\%) into polymer matrices may remarkably improve dimension stability, mechanical, thermal, optical, electrical, and gas barrier properties, and decrease the flammability. This happens due to the large contact area between polymer and clay on a nanoscale as reported on literature [1-11]. The incorporation of organoclays into polymer matrices has been known for 50 years and one of the pioneering works was from Toyota as reported by Cho and Paul [2]. To be compatible with polymer matrices, sodium smectite clays need to be modified by using quaternary ammonium salts with at least 12 carbon atoms in aqueous dispersions. In these dispersions, the clay particles or layers must be separated one from another and not be stacked in order to facilitate the introduction of the organic compounds. As a result, the clay exchangeable cations are replaced by the organic cations of the quaternary ammonium salt that are adsorbed on the negative sites of the clay surfaces. The obtained clay is known as organoclay [7-12]. Polyamide 66 (PA66) is an important engineering plastic, but PA66 matrix nanocomposites have been little investigated by researchers up to now [13-15].
The purpose of this paper is to analyze the effect of the Brazilian clay incorporation on the thermal behavior and morphology of Polyamide 66/clay nanocomposites.

\section{Experimental}

2.1. Materials. Polyamide 66 (PA66, Technyl A216, São Paulo/SP, Brazil) was supplied by Rhodia/Brazil and used; as a composite matrix. Na-montmorillonite (MMT, Brasgel PA, Boa Vista/PB, Northeast of Brazil) supplied by Bentonit União do Nordeste with a cation exchange capacity (CEC) of $90 \mathrm{meq} / 100 \mathrm{~g}$, and interlayer spacing $d_{001}=12.5 \AA$ was used as nanofiller. The quaternary ammonium salt esthearildimethylammonium chloride-Praepagen (P) with industrial grade, supplied by Clariant/Brazil, was used (as soon as it was received) for MMT clay modification.

2.2. Preparation of Organoclays. The Na-MMT clay was modified organically (named as organoclay) with quaternary ammonium salt according to the procedure described by Barbosa [4] and Araújo et al. [7-12, 16].

2.3. Preparation of Nanocomposites. PA66/unmodified clay (MMT) as well as PA66/modified clay (organoclay-OMMT) 
nanocomposites, containing 2 wt. $\%$ of clay, were melt compounded in a counterrotating twin-screw extruder (attached to a Haake System 90 Torque Rheometer) operating at $270-280^{\circ} \mathrm{C}$ and $40 \mathrm{rpm}$. Samples for tensile tests (ASTM D638) were injection molded in a Fluidmec machine at $280^{\circ} \mathrm{C}$. Before each processing, the PA66 pellets were dried under vacuum at $80^{\circ} \mathrm{C}$ for 24 hours. The rheological characterization of the nanocomposites containing $2 \mathrm{wt} . \%$ of clay was carried out in an intensive batch mixer Rheomix 600 equipped with roller blades attached to a Haake System 90, operating at $280^{\circ} \mathrm{C}, 60 \mathrm{rpm}$, and 10 minutes. The clays were added to PA66, after 2.5 minutes.

2.4. Characterization of Dispersibility of the Clay in Polymer Matrix. The structure of PA66/MMT and PA66/OMMT composites was characterized by X-ray diffraction (XRD) and transmission electron microscopy (TEM). XRD measurement was performed using an XRD-6000 Shimadzu diffractometer $(40 \mathrm{kV}, 30 \mathrm{~mA})$ with $2 \theta$ scan range of $2-30^{\circ}$ at room temperature, at a scanning speed of $2 \% \mathrm{~min}$ with $\mathrm{Cu}$ $(\lambda=0.154 \mathrm{~nm})$. TEM analysis was carried out in a Philips CM120 Equipment with $120 \mathrm{kV}$. Samples were cryogenically microtomed into ultrathin sections (25-50 nm thick) with a diamond knife using an RMC MT-7000 under cryogenic conditions $\left(-80^{\circ} \mathrm{C}\right)$ inside the microtoming chamber.

2.5. Differential Scanning Calorimetry (DSC). DSC analyses were carried out using a Shimadzu DSC-50 differential scanning calorimeter thermal analyzer. About $10 \mathrm{mg}$ of the polymer sample was weighed very accurately in the aluminum DSC pan and placed in the DSC cell. It was heated from 30 to $300^{\circ} \mathrm{C}$ at a rate of $20^{\circ} \mathrm{C} / \mathrm{min}$ under nitrogen atmosphere. The sample was kept for 5 minutes at this temperature to eliminate the heat history. The $\Delta H_{m o}$ values for PA66 matrix were taken as 195.9 J/g [14].

2.6. Thermogravimetry (TG). The thermal stability was measured by thermogravimetry using a Shimadzu TGA5lequipment, with a heating ramp of $20^{\circ} \mathrm{C} / \mathrm{min}$ in nitrogen and air atmospheres from 20 to $900^{\circ} \mathrm{C}$.

2.7. Heat Deflection Temperature (HDT). Heat deflection temperature (HDT) was obtained in a Davenport equipment, 09z64, with $1800 \mathrm{kPa}$, according to ASTM D648. The samples were immersed in a silicon oil bath at a rate of $120^{\circ} \mathrm{C} / \mathrm{h}$.

\section{Results and Discussion}

3.1. Structure of PA66/Clay Nanocomposites. Figure 1 presents the X-ray diffraction patterns for the PA66 systems with 2 wt.\% of unmodified (MMT) and modified clay (OMMT). The interlayer distancewas determined by the diffraction peak in the X-ray method, using the Bragg equation. It can be observed for the modified clay (OMMT) three peaks corresponding to an interlayer spacing $d_{001}$ of $29.2,19.2$, and $12.5 \AA$. The two first peaks indicate that the intercalation of the salt between the layers of clay has occurred. Another

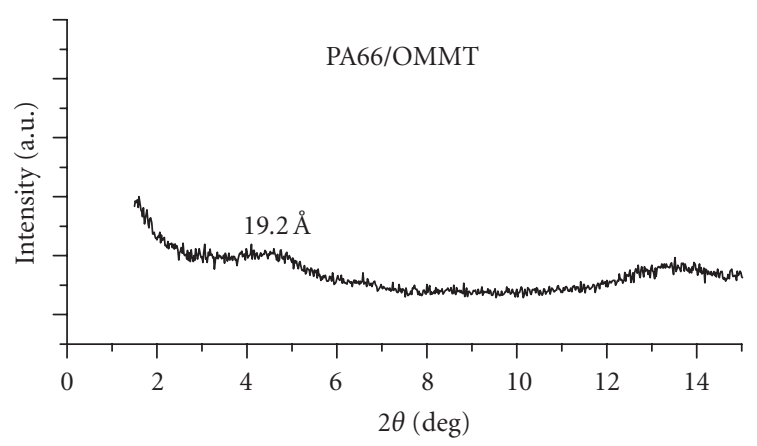

(a)

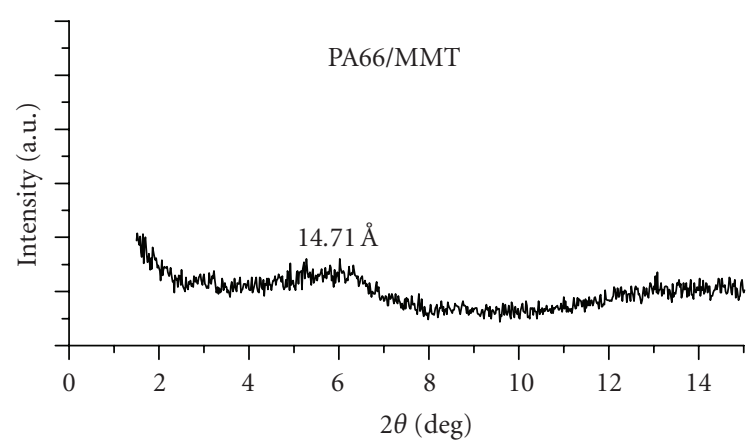

(b)

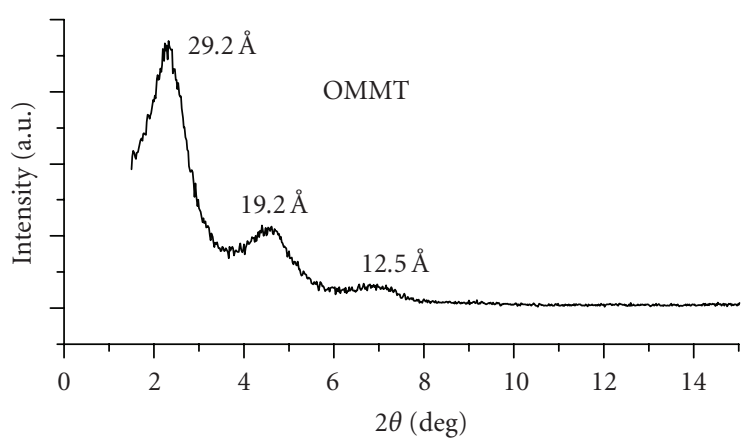

(c)

FIgURE 1: XRD patterns of montmorillonite clay modified with Praepagen salt (OMMT), PA66/MMT, and PA66/OMMT nanocomposites.

peak corresponding to interlayer spacings of $12.5 \AA$ ( $d_{001}$ for unmodified clay-MMT) is probably due to an incomplete ion exchange, with some residual Na-MMT remaining in the material, according to the literature $[7,8]$. The results indicated that the quaternary ammonium salt was intercalated between two basal planes of MMT, leading to an expansion of the interlayer spacing. It can be observed too for PA6/MMT system a diffraction peak around $14.71 \AA$, which is close to the distance of $12.5 \AA$ of the unmodified clay, indicating that the increase of the basal spacing practically did not occur. On the other hand, the sample of the nanocomposite of PA66 with the modified clay (OMMT) presented the displacement of the XRD peak toward a lower angle values, what represents an increase to $19.20 \AA$ in the basal spacing. It can be thus 


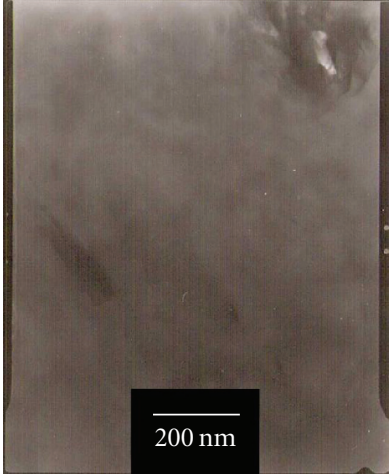

(a)

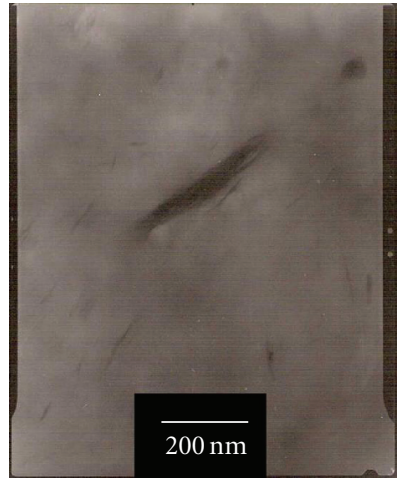

(b)
Figure 2: TEM photomicrographs of (a) PA66/MMT and (b) PA66/OMMT nanocomposites.

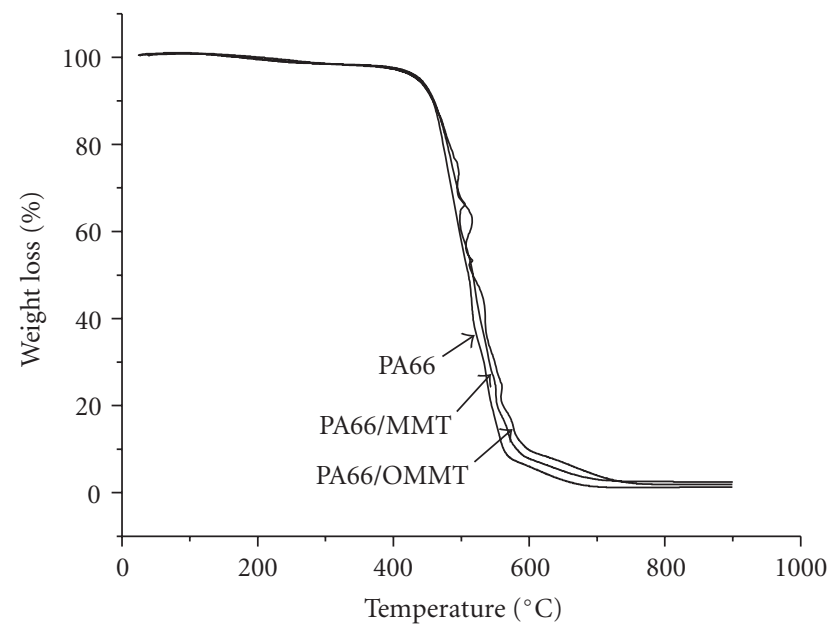

Figure 3: TG curves of PA66 and its nanocomposites in nitrogen atmosphere.

noticed that with the organoclay presence, the peak related to the PA66/unmodified clay interlayer spacing disappeared, and a new broad diffraction peak appeared. This peak can be due to the intercalation/partially exfoliation of the polymer chains between the layers of organoclay. These results will be confirmed by TEM.

Figure 2 shows the TEM images of the PA66 systems. In Figure 2(a), it can be seen clearly agglomerates of clay and in Figure 2(b) exists intercalated clay layers but it can be seen too several exfoliated clay layers present in the PA66 matrix. Therefore, the obtained PA66/OMMT systems are partially exfoliated nanocomposites according to the XRD pattern (Figure 1) and the literature [2, 3, 5, 13-15].

3.2. Thermal Behavior. Table 1 shows the melting and crystallization parameters of the pure PA66 and its mixtures obtained by DSC, respectively. It can be seen that there was no significant change in the melting and crystallization temperatures of the mixtures. On the other hand, it seems that the presence of the clay improved the heat of fusion,

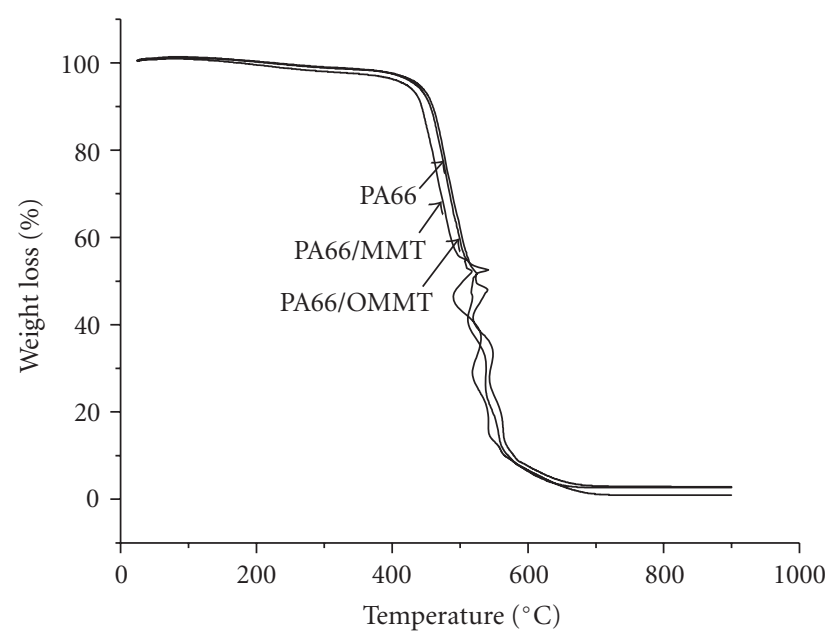

Figure 4: TG curves of PA66 and its nanocomposites in air atmosphere.

TABLe 1: Melting and crystallization parameters for PA66 and its nanocomposites. $T_{m}$ : melting temperature taken at the melt peak; $T_{c}$ : crystallization temperature taken at the crystallization peak; $\Delta H_{m}$ : heat of fusion due to PA66 melting, measured through the melting peak; $X_{c}$ : degree of crystallinity, taken from $\Delta H_{m} / \Delta H_{m o}$; $\Delta H_{m o}$ : heat of fusion for PA66, $100 \%$ crystalline, $195.9 \mathrm{~J} / \mathrm{g}$ [14].

\begin{tabular}{lcccc}
\hline & \multicolumn{2}{c}{ Heating } & Cooling & \\
Materials & $T_{m}\left({ }^{\circ} \mathrm{C}\right)$ & $\Delta H_{m}(\mathrm{~J} / \mathrm{g})$ & $T_{c}\left({ }^{\circ} \mathrm{C}\right)$ & $X_{c}(\%)$ \\
\hline PA66 & 266.98 & 50.07 & 223.45 & 25.55 \\
PA66/MMT & 263.82 & 60.43 & 224.74 & 30.23 \\
PA66/OMMT & 263.67 & 60.80 & 223.11 & 30.41 \\
\hline
\end{tabular}

which leaded to higher crystallinity degree. Probably, the clay acts as nucleation agent in the matrix.

In order to investigate the effect of the organoclay on the thermal stability of PA66/clay nanocomposite, the TG analysis of the systems is presented. The thermal stability of PA66/clay nanocomposites is a little improved with the presence of the organoclay in nitrogen atmosphere, as pointed out in Figure 3. Pure PA66 degrades a little faster than PA66/clay nanocomposites, that is, the nanocomposites are stable up to $\sim 400^{\circ} \mathrm{C}$. Figure 4 shows TG curves using air atmosphere. In these conditions, it can be seen that the nanocomposite containing organoclay presents thermal stability a little superior than PA66/MMT. This suggests that at the range of the used processing temperatures, the degradation of the system did not occur. Apparently, the organoclay has two opposing functions in the thermal stability of the nanocomposites, one is due to barrier property to the oxygen and the other is due to the catalysis effect toward the degradation of the polymer, but the barrier effect is predominant with the addition of low fraction of clay to the polymer matrix, as observed in this work. Only with increasing loading, the catalyzing effect rapidly rises and becomes dominant and the thermal stability of the nanocomposites decreases, according to Araújo et al. [8] and Zhao et al. [17]. 


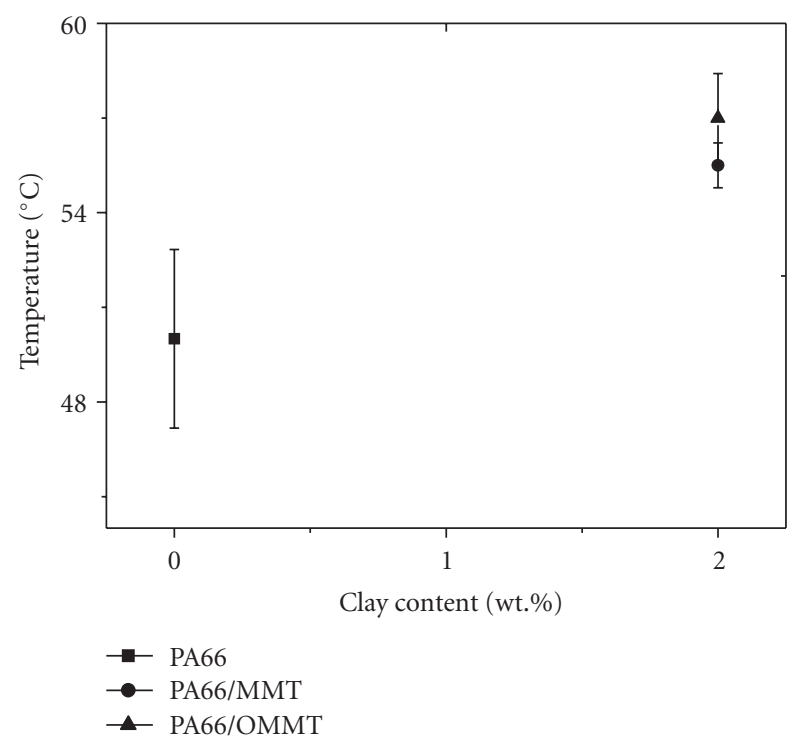

Figure 5: Heat deflection temperature of PA66 and its nanocomposites.

3.3. Heat Deflection Temperature (HDT). The heat deflection temperature (HDT) can be used to simulate the polymer application in temperatures above the environment temperature and to evaluate the compatibility of the polymer systems. Figure 5 shows the obtained data for HDT of the nanocomposites and pure PA66. The HDT of the pure PA66 stayed in the range of $50^{\circ} \mathrm{C}$ and for nanocomposites in the range of $56^{\circ} \mathrm{C}$. Of the point of view technologic, these values are very interesting since the literature in general mentions that the formation of nanoparticles increases the HDT, the rigidity of the system, and the barrier properties. The presence of organoclay in the PA66 matrix increased the HDT compared to pure PA66.

\section{Conclusions}

Polyamide 66/Brazilian clay nanocomposites were producedvia direct melt intercalation. The obtained PA66/organoclay nanocomposites presented partially exfoliated structure. XRD analysis showed that the salt was intercalated between two basal planes of montmorillonite clay. Incorporation of the organoclay improved the thermal stability of PA66. As expected, HDT's properties presented very interesting values for the nanocomposites and larger ones for matrix. This also indicates that the Brazilian clay can be used as a nanoparticle in PA66 nanocomposites.

\section{Acknowledgments}

The authors thank Rhodia, Bentonit União Nordeste, Clariant, all Brazilian industries, Renami (Rede de Nanotecnologia Molecular e de Interfaces), CTPETRO/MCT/CNPq and $\mathrm{MCT} / \mathrm{CNPq} /$ Universal for financial support, MSc. Pankaj Agrawal/UFCG/Brazil and Doutorado em Engenharia de Processos/UFCG/Brazil.

\section{References}

[1] S. A. Body, M. M. Mortland, and C. T. Chiou, "Sorption characteristics of organic compounds on hexadecyltrimethyl ammonium-smectite," Soil Science Society of America Journal, vol. 52, pp. 652-657, 1988.

[2] J. W. Cho and D. R. Paul, "Nylon 6 nanocomposites by melt compounding," Polymer, vol. 42, no. 3, pp. 1083-1094, 2001.

[3] M. Zanetti and L. Costa, "Preparation and combustion behaviour of polymer/layered silicate nanocomposites based upon PE and EVA," Polymer, vol. 45, no. 13, pp. 4367-4373, 2004.

[4] R. Barbosa, Effect of quaternary ammonium salts in the national bentonite clay organophilization for the development of HDPE nanocomposites, M.S. thesis, University of Campina Grande, Campina Grande, Brazil, 2005.

[5] S. Wang, Y. Hu, Q. Zhongkai, Z. Wang, Z. Chen, and W. Fan, "Preparation and flammability properties of polyethylene/clay nanocomposites by melt intercalation method from $\mathrm{Na}^{+}$ montmorillonite," Materials Letters, vol. 57, no. 18, pp. 26752678, 2003.

[6] C. Zilg, P. Reichert, F. Dietsche, T. Engelardt, and R. Mülhaupt, "Pesquisadores desenvolvem nanocompósitos que atuam como cargas com diferentes finalidades," Plástico Industrial, pp. 64-74, February 2000.

[7] R. Barbosa, E. M. Araújo, T. J. A. Melo, and E. N. Ito, "Comparison of flammability behavior of polyethylene/Brazilian clay nanocomposites and polyethylene/flame retardants," Materials Letters, vol. 61, no. 11-12, pp. 2575-2578, 2007.

[8] E. M. Araújo, R. Barbosa, A. W. B. Rodrigues, T. J. A. Melo, and E. N. Ito, "Processing and characterization of polyethylene/Brazilian clay nanocomposites," Materials Science and Engineering A, vol. 445-446, pp. 141-147, 2007.

[9] E. M. Araújo, R. Barbosa, A. D. Oliveira, C. R. S. Morais, T. J. A. deMélo, and A. G. Souza, "Thermal and mechanical properties of PE/organoclay nanocomposites," Journal of Thermal Analysis and Calorimetry, vol. 87, no. 3, pp. 811-814, 2007.

[10] E. M. Araújo, K. D. Araujo, and T. R. Gouveia, "Physical properties of nylon 66/organoclay nanocomposites," Materials Science Forum, vol. 530-531, pp. 702-708, 2006.

[11] E. M. Araújo, T. J. A. Mélo, L. N. L. Santana, et al., “The influence of organo-bentonite clay on the processing and mechanical properties of nylon 6 and polystyrene composites," Materials Science and Engineering B, vol. 112, no. 2-3, pp. 175178, 2004.

[12] E. M. Araújo, R. Barbosa, C. R. S. Morais, L. E. B. Soledade, A. G. Souza, and M. Q. Vieira, "Effects of organoclays on the thermal processing of pe/clay nanocomposites," Journal of Thermal Analysis and Calorimetry, vol. 90, no. 3, pp. 841-848, 2007.

[13] H. Qin, Q. Su, S. Zhang, B. Zhao, and M. Yang, "Thermal stability and flammability of polyamide 66/montmorillonite nanocomposites," Polymer, vol. 44, no. 24, pp. 7533-7538, 2003.

[14] F. Chavarria and D. R. Paul, "Comparison of nanocomposites based on nylon 6 and nylon 66," Polymer, vol. 45, no. 25, pp. 8501-8515, 2004.

[15] X. Liu, Q. Wu, and L. A. Berglund, "Polymorphism in polyamide 66/clay nanocomposites," Polymer, vol. 43, no. 18, pp. 4967-4972, 2002. 
[16] R. Barbosa, E. M. Araújo, T. J. A. Melo, E. N. Ito, and E. Hage Jr., "Influence of clay incorporation on the physical properties of polyethylene/Brazilian clay nanocomposites," Journal of Nanoscience and Nanotechnology, vol. 8, no. 4, pp. 1937-1941, 2008.

[17] C. Zhao, H. Qin, F. Gong, M. Feng, S. Zhang, and M. Yang, "Mechanical, thermal and flammability properties of polyethylene/clay nanocomposites," Polymer Degradation and Stability, vol. 87, no. 1, pp. 183-189, 2005. 

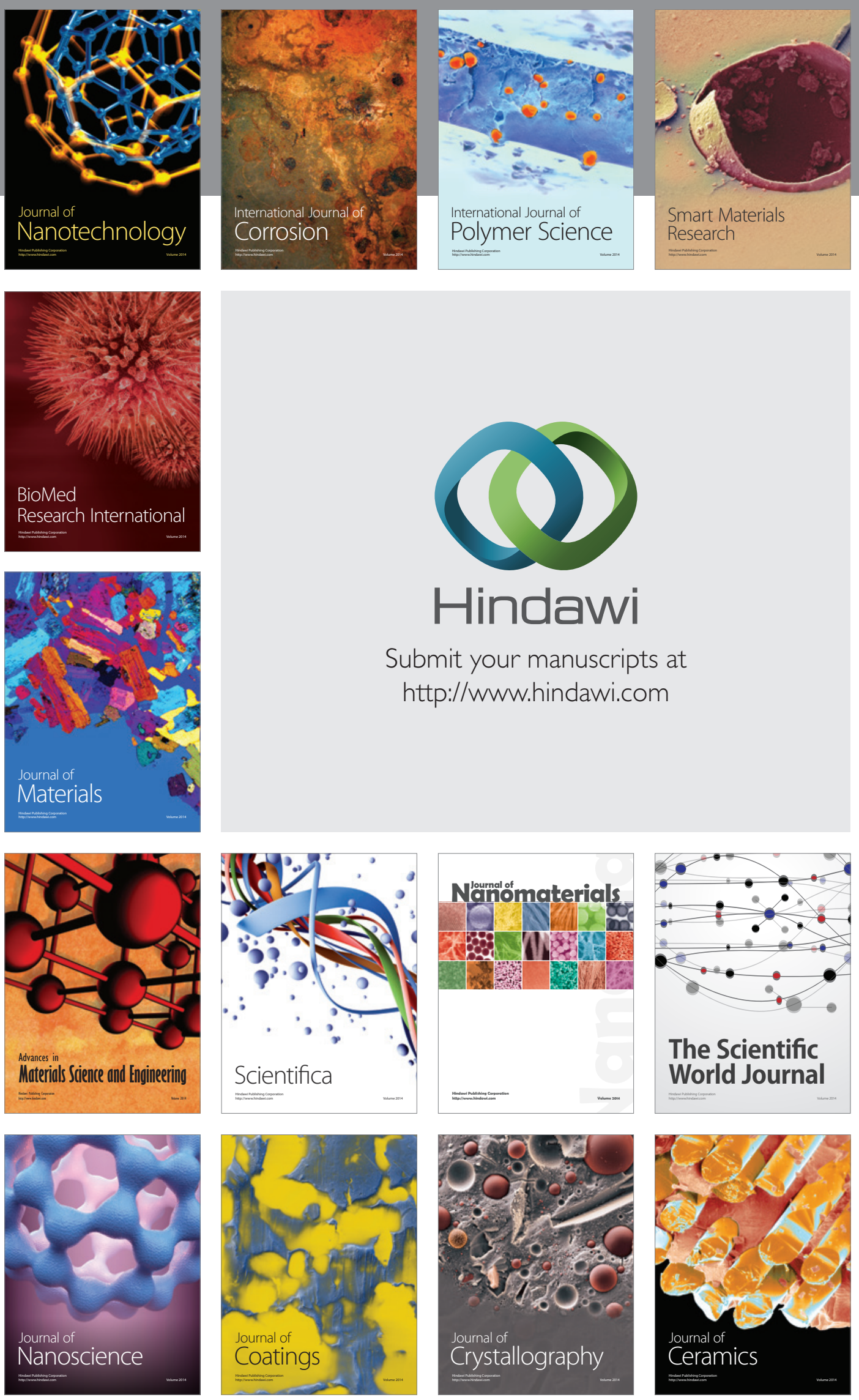

The Scientific World Journal

Submit your manuscripts at

http://www.hindawi.com

\section{World Journal}

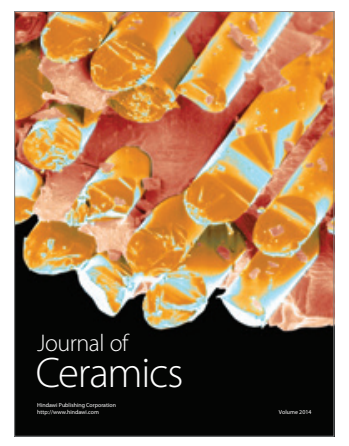

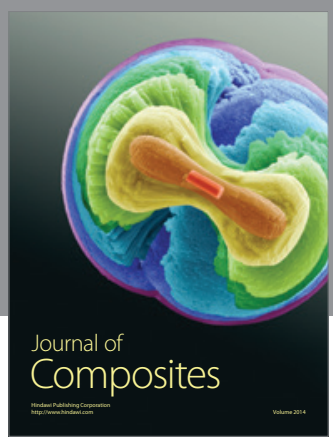
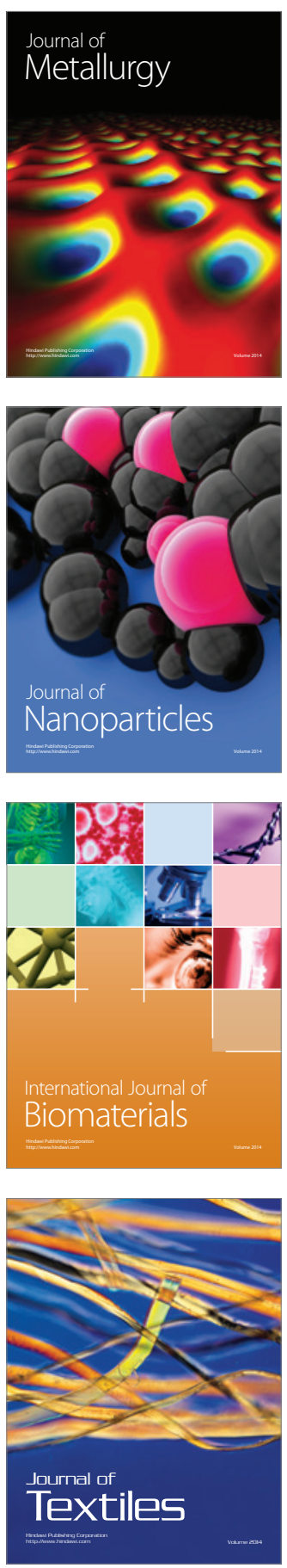